\title{
Perancangan dan Implementasi Multi-Input Konverter Buck Untuk Pengisian Baterai Menggunakan Panel Surya dan Turbin Angin
}

\author{
Zainul Arifin, Dedet Candra Riawan, ST., M.Eng., Ph.D dan Heri Suryoatmojo, ST., MT., Ph.D \\ Jurusan Teknik Elektro, Fakultas Teknologi Industri, Institut Teknologi Sepuluh Nopember (ITS) \\ J1. Arief Rahman Hakim, Surabaya 60111 \\ E-mail: zainul12@mhs.ee.its.ac.id ; dedet@ee.its.ac.id ; suryomgt@ee.its.ac.id
}

\begin{abstract}
Abstrak - Baterai adalah sebuah peralatan listrik yang berfungsi untuk menyimpan energi pada peralatan elektrik, elektronik, maupun peralatan otomotif. Perkembangan teknologi pembangkitan tenaga listrik dengan memanfaatkan sumber energi terbarukan saat ini berkembang pesat sehingga diharapkan mampu menjadi sumber listrik alternatif. Untuk membuat sistem yang diharapkan dilakukan dengan cara menggabungkan sumber-sumber energi listrik yang ramah lingkungan dan melimpah seperti sel surya dan turbin angin.Tujuan dari penggunaan teknologi Konverter multi-input (MIC) adalah untuk menggabungkan keluaran tegangan panel surya dan turbin angin agar kedua sumber dapat bekerja secara mandiri atau pun bersama-sama. Konverter multi-input adalah konverter yang mempunyai input lebih dari satu. Pada Tugas Akhir ini daya yang dihasilkan dari $M I C$ akan digunakan untuk pengisian baterai. Pengoperasian MIC dilakukan dengan mengatur duty cycle yang berupa modulator PWM yang dipasang pada sakelar masing-masing sumber. Sedangkan tegangan keluaran dari $M I C$ dijaga konstan untuk pengisian baterai dengan mode constant voltage. Dalam implementasi dapat dibuktikan bahwa dengan menggunakan dua sumber input tegangan dan beban resistor, tegangan keluaran konverter tetap terjaga konstan
\end{abstract}

Kata Kunci: Panel surya, Baterai, konverter DC-DC, Konverter multi-input

\section{PENDAHULUAN}

Perkembangan pemanfaatan sumber energi terbarukan seperti energi surya dan energi angin menjadi energi listrik saat ini yang telah meningkat secara signifikan. Penggunaan energi terbarukan tersebut juga diiringi oleh petumbuhan teknologi elektronika daya yang cepat dan semakin canggih, namun ketersedian energi matahari dan energi angin bergantung pada waktu, cuaca dan musim. Contoh kasus yang pertama adalah saat musim kemarau, energi matahari berlimpah akan tetapi kecepatan angin pelan, yang kedua saat musim penghujan, karena mendung cahaya matahari tertutup awan sedangkan angin tertiup kencang. Karena melihat kenyataan itu dibuatlah teknik hybrid dimana tenaga panel surya dan turbin angin dipadukan sehingga lebih handal untuk menyuplai tenaga secara kontinu dari pada bekerja secara terpisah[1]-[2].

Teknik hybrid yang sekarang banyak digunakan adalah menggabungkan beberapa jenis pembangkit listrik yang tidak dapat diperbaharui maupun yang dapat diperbaharui, Contohnya seperti pembangkit energi angin, surya, dan diesel. Kontribusi dari tugas akhir ini adalah Konverter multi-input (MIC) digunakan sebagai solusi alternatif untuk mengkombinasi sumber energi terbarukan yang ada sehingga dapat menyederhanakan dalam mengatur dua sumber yang tersedia, menyederhanakan desain dan mengurangi biaya. Terdapat sebuah kontrol dengan PWM pada setiap sumber agar dapat bekerja bergantian sesuai Duty cycle masingmasing [3]. Kedua input dimasukan kedalam konverter buck dimana tegangan keluaran akan lebih kecil dari tegangan input sehingga dapat dikondisikan untuk beban yang mempunyai daya kecil[4].

Dengan mengacu pada rentang tegangan pengisian baterai lead acid, bisa ditentukan nilai tegangan keluaran konverter yang akan dikeluarkan nantinya. Dimana tegangan keluaran konverter harus lebih besar daripada tegangan baterai. Dengan begitu pengisian baterai dapat dilakukan[5]-[6].

\section{URAIAN PENELITIAN}

\section{A. Konverter DC-DC multi-input konverter buck}

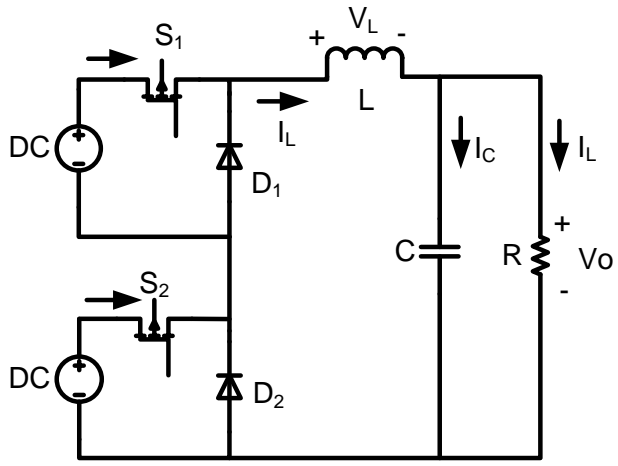

Gambar 1. Topologi Konverter.

Ketika sakelar pertama $S_{1}$ dan sakelar kedua $S_{2}$ dimatikan, dioda $D 1$ dan $D 2$ akanakan memberikan jalan by pass agar arus induktor mengalir terus menerus.Dengan menerapkan skema Kontrol PWM untuk menyalakan sakelar $S_{1}$ dan $S_{2}$, multi-input yang direncanakan bisa mengalirkan dua sumber tegangan secara sendiri-sendiri maupun gabungan. 


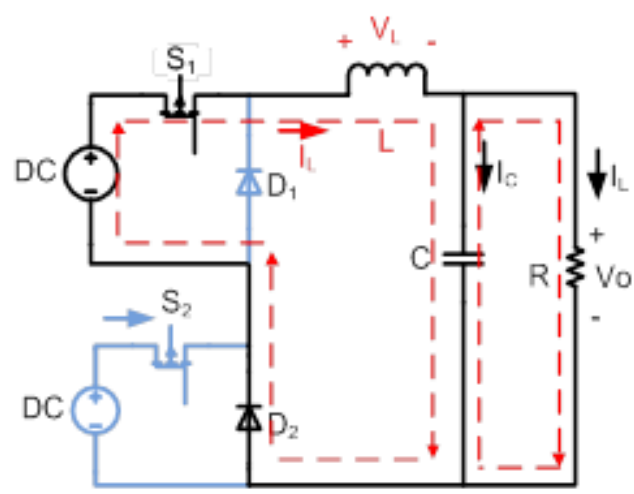

(a)

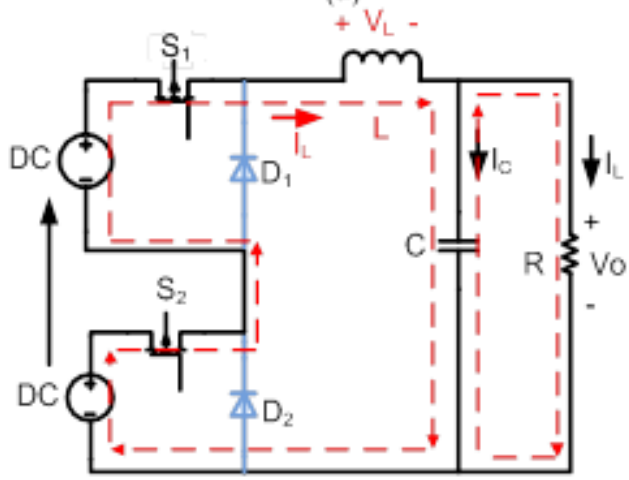

(c)

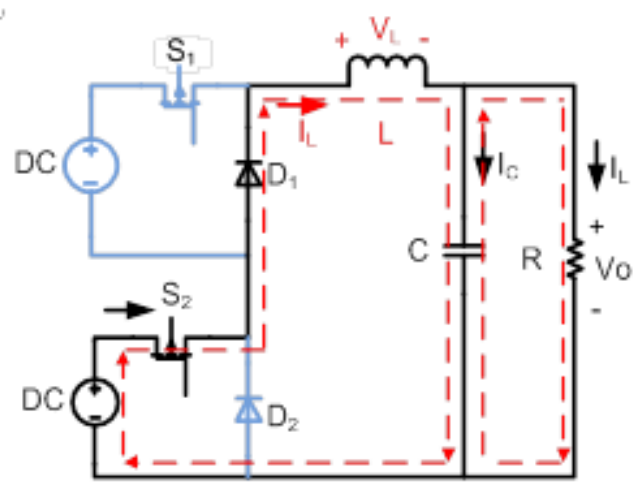

(b)

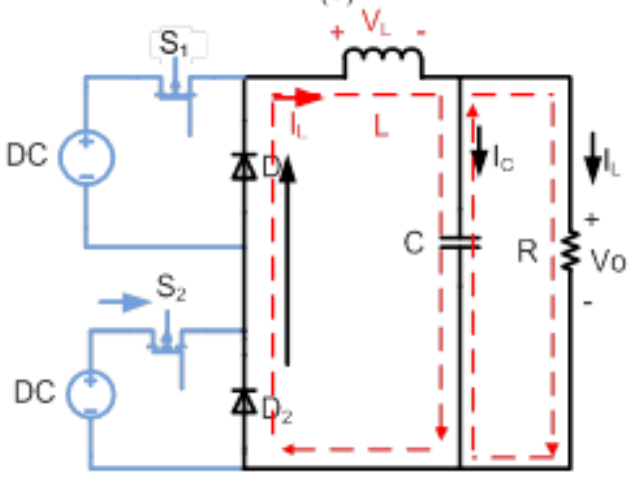

(d)

Gambar 2. Operasi konverter buck multi-input (a) mode 1 (b) mode 2, (c) mode 3, (d) mode 4

\section{B. Mode Operasi Konverter}

Konverter DC-DC multi-input buck converter memiliki empat mode operasi dalam satu periode penyakelaran. Dalam melakukan analisis terhadap mode operasi konverter, diasumsikan bahwa semua komponen dianggap dan konverter beroperasi secara continuous-continuous conduction mode $(\mathrm{C}$ CCM) atau arus induktor $i_{L}$ selalu kontinu [3].

1. Mode 1

Pada saat (S1 : ON / S2 : OFF) sakelar satu (S1) diaktifkan dan sakelar dua (S2) dimatikan. S1 konduksi, Dioda D1 bekerja reverse bias dan dianggap sebagai rangkaian terbuka, dan disisi lain V2 mati sehingga dioda D2 akan menyediakan jalur by pass untuk induktor sesuai ditunjukan pada Gambar 2 (a). Dalam mode ini V1 akan menyuplai komponen penyimpanan daya induktor L dan kapasitor (C) serta beban (R).

2. Mode 2

Pada saat (S1 : OFF / S2 : ON) sakelar satu (S1) dimatikan dan sakelar dua (S2) diaktifkan. S2 konduksi, Dioda D2 bekerja reverse bias dan dianggap sebagai rangkaian terbuka, dan disisi lain V1 mati sehingga dioda D1 akan menyediakan jalur by pass untuk induktor sesuai ditunjukan pada Gambar 2 (b). Dalam mode ini V2 akan menyuplai komponen penyimpanan daya induktor L dan kapasitor (C) serta beban (R).

3. Mode 3

Pada saat (S1 : ON / S2 : ON) sakelar satu (S1) dan sakelar dua (S2) diaktifkan. Sakelar S1 dan S2 konduksi, Dioda D1 dan dioda D2 bekerja reverse bias dan dianggap sebagai rangkaian terbuka, dan disisi lain V1 dan V2 tersusun seri sesuai ditunjukan pada Gambar 2 (c).pada mode ini V1dan V2 yang tersusun seri menyuplai komponen penyimpanan daya induktor L dan kapasitor (C) serta beban (R).

\section{Mode 4}

Pada saat (S1 : OFF / S2 : OFF) sakelar satu (S1) dan sakelar dua (S2) dimatikan. Sakelar S1 dan S2 isolasi, Dioda D1 dan dioda D2 bekerja forward bias dan dianggap sebagai rangkaian terbuka. Disisi lain V1 dan V2 mati sehingga dioda D1 dan dioda D2 akan menyediakan jalur by pass untuk induktor sesuai ditunjukan pada Gambar 2(d). Dalam mode ini V1 dan V2 tidak menyuplai ke beban namun ada arus sisa dari induktor menyuplai kapasitor (C) dan beban (R).

\section{Analisis Persamaan konverter multi-input}

Untuk menentukan besar nilai komponen yang digunakan pada konverter multi-input buck converter seperti duty cycle 1 $D_{1}$, duty cycle $2 D_{2}$, kapasitor $C$, induktor $L$, ripple $\operatorname{arus}\left(\Delta I_{L}\right)$ maupun ripple tegangan keluaran $\left(\Delta V_{o}\right)$ keempat mode sebelumnya akan digunakan. Adapun mode 1 dapat diperoleh persamaan sebagai berikut :

$$
\begin{aligned}
& V_{L}=L \frac{d i}{d t} \\
& V_{L}=V_{1}-V_{o} \\
& L \frac{d i_{L}}{d t}=V_{1}-V_{o}
\end{aligned}
$$




$$
\Delta i_{L}=\frac{V_{1}-V o}{L}(D T)
$$

Selanjutnya pada mode 2 yang ditunjukan pada Gambar 2 (b) didapatkan persamaan sebagai berikut:

$$
\begin{aligned}
& V_{L}=V_{2}-V_{O}=L \frac{d i_{L}}{d t} \\
& L \frac{d i_{L}}{d t}=V_{2}-V_{O} \\
& \Delta i_{L}=\frac{V_{2}-V_{O}}{L}(D T)
\end{aligned}
$$

Selanjutnya pada mode 3 yang ditunjukan pada Gambar 2 (c) didapatkan persamaan sebagai berikut:

$$
\begin{aligned}
& V_{L}=V_{1}+V_{2}-V o=L \frac{d i_{L}}{d t} \\
& L \frac{d i_{L}}{d t}=V_{1}+V_{2}-V o \\
& d i_{L}=\frac{V_{1}+V_{2}-V o}{L} D T \\
& \left(\Delta i_{L}\right)_{\text {Tertutup }}=\frac{V_{1}+V_{2}-V o}{L} D T
\end{aligned}
$$

Dari persamaan 2.11 bisa diketahui nilai dari ripple arus induktor $\left(\Delta I_{L}\right)$.Selanjutnya pada mode 4 yang ditunjukan pada Gambar 2 (d) didapatkan persamaan sebagai berikut:

$$
\begin{aligned}
& V_{L}=-V_{O}=L \frac{d i_{L}}{d t} \\
& \frac{d i_{L}}{d t}=\frac{-V o}{L} \\
& \frac{\Delta i_{L}}{\Delta t}=\frac{\Delta i_{L}}{(1-D) T}=\frac{-V o}{L} \\
& \left(\Delta i_{L}\right)_{\text {terbuka }}=\frac{-V o}{L}(1-D) T
\end{aligned}
$$

Dengan mengaplikasikan prinsip induktor volt-second balance dan mengkobinasikan persamaan (2.8), (2.5) dan (2.12) dihasilkan persamaan:

$$
\begin{gathered}
\left(V_{1}+V_{2}-V_{O}\right) d t+\int_{D 1 T}^{D 2 T}\left(V_{2}-V_{O}\right) d t \\
+\int_{D 2 T}^{T}\left(-V_{o}\right) d t=0
\end{gathered}
$$

Dari persamaan 2.16 diatas diperoleh persamaan dasar untuk konverter buck multi-input seperti persamaan:

$$
V_{O}=V_{1} D_{1}+V_{2} D_{2}
$$

Induktor diasumsikan mempunyai induktansi besar sehingga ripple arus diabaikan. Ketika $S_{1}$ dan $S_{2}$ aktif arus yang dihasilkan $V_{l}$ dan $V_{2}\left(I_{1}\right.$ dan $\left.I_{2}\right)$ sama dengan arus yang mengalir di induktor $\left(I_{L}\right)$ sehingga arus rata-rata yang dapat dimasukan dapat ditulis dalam persamaan :

$$
\begin{aligned}
& I_{S 1}=d_{1} I_{1}=d_{1} I_{0} \\
& I_{S 2}=d_{2} I_{2}=d_{2} I_{0}
\end{aligned}
$$

\section{DESAIN, SIMULASI DAN IMPLEMENTASI}

A. Desain

Desain konverter dilakukan untuk menentukan parameter rangkaian dengan memperhitungkan peralatan yang terdapat di laboratorium dan komponen yang tersedia di pasaran, sehingga mempermudah proses implementasi prototype konverter. Tabel 1 di bawah ini menunjukkan parameter awal yang digunakan sebagai acuan dalam proses desain konverter.

Tabel 1.

Spesifikasi Awal Desain Konverter

\begin{tabular}{lc}
\multicolumn{2}{c}{ Spesifikasi Awal Desain Konverter } \\
\hline \hline \multicolumn{1}{c}{ Parameter } & Nilai \\
\hline & \\
Daya Output $P_{O}$ & $30 \mathrm{Watt}$ \\
Tegangan Output $V_{O}$ & 13.8 Volt \\
Tegangan Input 1 VI & 17 Volt \\
Tegangan Input 2 V2 & $24 \mathrm{Volt}$ \\
Switching Frequency $(f)$ & $40 \mathrm{kHz}$ \\
Ripple $V_{O}\left(\Delta V_{O}\right)$ & $1 \%$ \\
Ripple $I_{L}\left(\Delta I_{L}\right)$ & $30 \%$ \\
\end{tabular}

Tegangan output multi-input buck converter harus dijaga konstan sebesar 13.8 Volt dengan bekerja-samanya dua duty cycle. Konverter multi-input ini bekerja pada tegangan input $V_{1}=17$ Volt dan $V_{2}=24$ Volt. Diasumsikan duty cycle $1 D_{l}=$ 50\% Dari persamaan 2.17 dapat diperoleh persamaan duty cycle sebagai berikut:

$$
\begin{aligned}
& D_{2}=\frac{V_{O}-V_{1} D_{1}}{V_{2}} \\
& D_{2}=\frac{13.8-(17 * 0.5)}{24}=0.22
\end{aligned}
$$

Dari persamaan 2.11 ,jika tegangan input $1 \mathrm{Vl}$ ditambahkan dengan tegangan input $2 V_{2}$ sama dengan $V$ sumber $\mathrm{Vs}$, $V_{1}+V_{2}=V s$ diperoleh persamaan dan perhitungan sebagai berikut :

$$
\begin{aligned}
& L=\frac{V_{O}\left(1-\max \left(D_{1}, D_{2}\right)\right.}{0.3\left(\frac{P_{O}}{V \text { in }}\right) \cdot f} \\
& L=\frac{13.8(1-\max (0.5,0.22))}{0.3\left(\frac{30}{17+24}\right) \cdot 40000^{2}}=785.8 \mu \mathrm{H}
\end{aligned}
$$

Dalam implementasinya nilai induktor dibuat lebih besar dari perhitungan dan dibuat induktor dengan nilai sebesar $800 \mu \mathrm{H}$ 
Dari persamaan muatan yang tersimpan pada tegangan output. Adapun persamaan umtuk memperoleh nilai kapasitor adalah sebagai berikut :

$$
\begin{aligned}
& Q=C V_{O} \\
& \Delta Q=C \Delta V_{O} \\
& \Delta V_{O}=\frac{\Delta Q}{C}
\end{aligned}
$$

Jika perubahan pengisian pada $\Delta \mathrm{Q}$ adalah segitiga diatas sumbu X maka dihasilkan persamaan :

$$
\begin{aligned}
& \Delta Q=\frac{1}{2}\left(\frac{T}{2}\right)\left(\frac{\Delta i_{L}}{2}\right)=\frac{T \Delta i_{L}}{8} \\
& \Delta V_{O}=\frac{T \Delta i_{L}}{8 C} \\
& \Delta V_{O}=\frac{T V_{O}}{8 C L}(1-D) T=\frac{V_{O}(1-D)}{8 L C f^{2}} \\
& \frac{\Delta V_{O}}{V_{O}}=\frac{1-D}{8 L C f^{2}} \\
& C=\frac{1-m a x\left(D_{1}, D_{2}\right)}{8 L\left(\frac{\Delta V_{O}}{V_{O}}\right) \cdot f^{2}} \\
& C=\frac{1-0.5}{8 \cdot 0.785 \cdot 10^{-3} \cdot 0.01 \cdot 40000^{2}}=4.97 \mu F
\end{aligned}
$$

Dalam implementasinya nilai kapasitor disesuaikan dengan kapasitor yang tersedia di pasaran, maka dua kapasitor $10 \mu \mathrm{F}$ disusun seri sehingga menghasilkan nilai $5 \mu \mathrm{F}$.

\section{B. Simulasi}

Simulasi dilakukan menggunakan software dengan nilai dari parameter-parameter yang telah dihitung. Untuk nilai induktansi bocor $L_{K P}$ dimasukkan sebesar $5 \mu \mathrm{H}$ yang diperoleh dari pengukuran induktor-kopel hasil implementasi menggunakan LCR meter. Simulasi dilakukan dalam kondisi tunak dengan $V_{l}=17$ Volt, $V_{2}=24$ Volt, $D_{l}=0,6$ dan secara perhitungan diperoleh nilai $\mathrm{D}_{2}=0.22$.

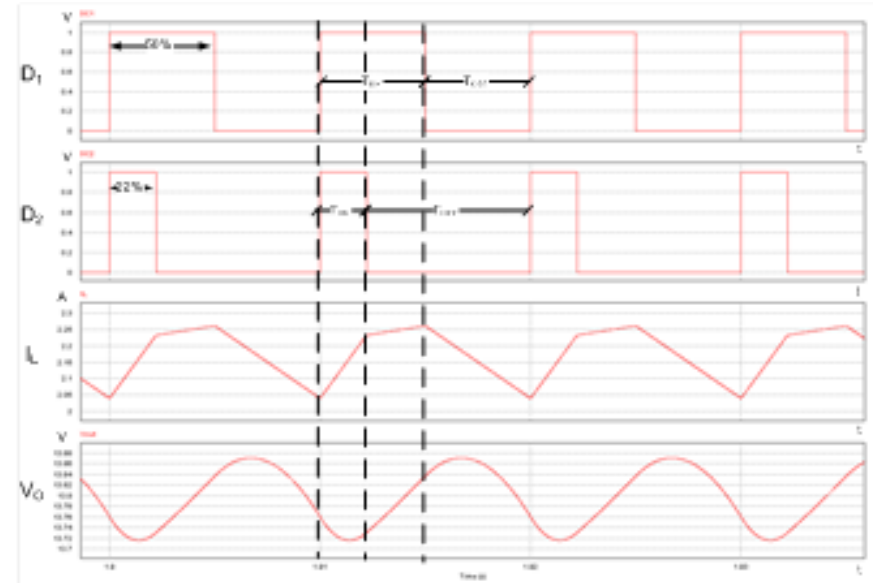

Gambar 3. Gelombang Arus Induktor dan Tegangan Kapasitor.

\section{Implementasi}

Implementasi dilakukan untuk mengetahui kinerja konverter berdasarkan desain dan simulasi yang telah dilakukan. Tabel 2 menunjukkan spesifikasi komponen yang digunakan. Nilai ini diperoleh dari hasil perhitungan dan disesuaikan dengan komponen yang tersedia di pasaran.

Tabel 2.

Spesifikasi Komponen Rangkaian Konverter

\begin{tabular}{cc}
\hline \hline Komponen & Nilai \\
\hline & \\
Induktor $L_{l}$ & $800 \mu \mathrm{H}$ \\
Kapasitor $C$ & $5 \mathrm{uF} / 100 \mathrm{~V}$ \\
Dioda & MUR1560 \\
MOSFET & IRF540 \\
\hline
\end{tabular}

Sesuai dengan komponen pada Tabel 2, Gambar 4 di dibawah menunjukkan hasil implementasi dari konverter DCDC rasio tinggi dengan induktor-kopel dan dioda-kapasitor.

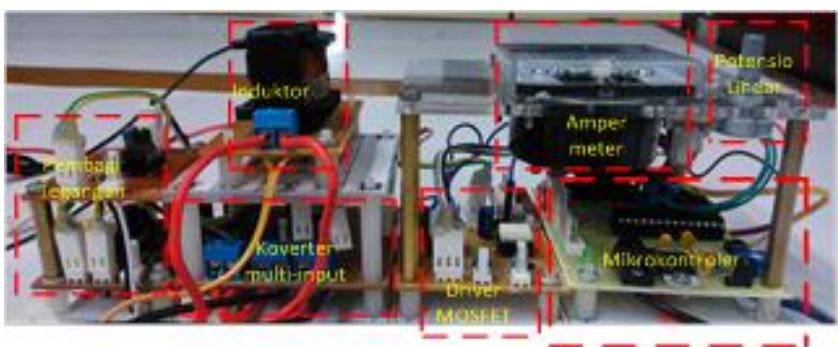

(a)

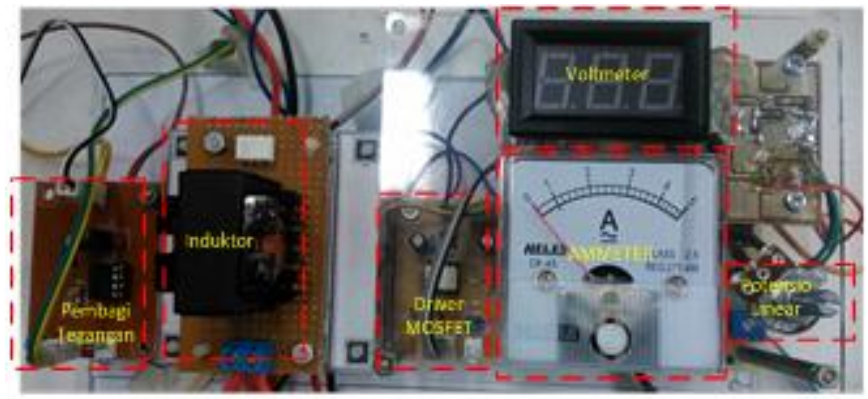

(b)

Gambar 4. Hasil Implementasi Alat (a) Tampak samping (b) Tampak atas

\section{PENGUJIAN}

\section{A. Pengujian Gelombang Pensakelaran}

Pengujian sinyal PWM dan pensakelaran dilakukan untuk mengetahui pakah bentuk gelombang output PWM dan proses pensakelaran pada dioda dan MOSFET sudah bekerja sebagaimana mestinya. Pengujian dilakukan dengan menggunakan osiloskop dengan memberikan tegangan input pertama $\mathrm{V}_{1}=15 \mathrm{~V}$, tegangan input kedua $\mathrm{V}_{2}=20 \mathrm{~V}$, duty cycle pertama $\mathrm{D} 1=0.28 \%$ dan duty cycle kedua $\mathrm{D}_{2}=0.48 \%$ sebagaimana yang tertera pada Tabel 1 . frekuensi switching yang digunakan adalah $40 \mathrm{kHz}$, sehingga besar periode gelombang PWM dan pensakelaran konverter adalah $25 \mu \mathrm{s}$. 


\section{B. Pengujian Arus induktor terhadap duty cycle}

Dari Gambar 4.2 dapat diketahui bahwa dioda D1 dan D2 sudah bekerja sebagaimana mestinya yaitu sesuai dengan mode operasi konverter dan hasil simulasi. Saat tegangan MOSFET G-S 1 atau $\mathrm{V}_{\mathrm{GS} 1}$ dalam kondisi high $\left(V_{G S I}=8.6 \mathrm{~V}\right)$ maka kondisi dioda D1 reverse bias. Begitu juga saat tegangan MOSFET G-S $2\left(V_{G S I}\right)$ atau $\mathrm{V}_{\mathrm{GS} 1}$ dalam kondisi high $\left(\mathrm{V}_{\mathrm{GS} 1}=11 \mathrm{~V}\right)$ maka kondisi dioda $D_{2}$ juga reverse bias. Saat tegangan MOSFET G-S $1\left(V_{G S I}\right)$ dalam kondisi low $\left(V_{G S I}\right.$ $=0 \mathrm{~V}$ ) proses sebaliknya terjadi. Begitu pula pada $V_{G S 2}$ dan $D_{2}$.

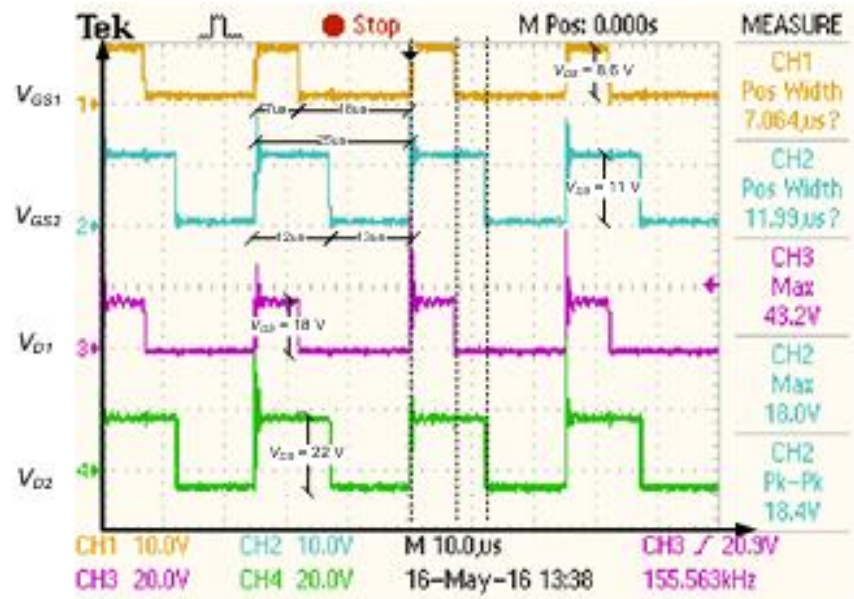

Gambar 5. Bentuk Gelombang Penyakelaran pada Dioda dan MOSFET

\section{Pengujian Arus Induktor dan Tegangan Kapasitor}

Bentuk gelombang hasil pengujian arus induktor (IL) saat konverter diberi tegangan input $\mathrm{V} 1=15 \mathrm{~V} ; \mathrm{V} 2=20 \mathrm{~V}$ dan duty cycle $1=28 \%$; duty cycle $2=48 \%$ dapat dilihat pada Gambar 6. Dari Gambar tersebut dapat dianalisis bahwa saat VGS konduksi, tegangan Induktor VL bernilai poisitif. Induktor mengalami charging energi sehingga arus induktor IL mengalami peningkatan. Sedangkan saat VGS pada kondisi low tegangan induktor $V_{L}$ bernilai negatif. Induktor mengalami discharging energi sehingga arus induktor IL mengalami penurunan. Selain itu nilai arus induktor selalu positif (lebih dari 0). Hal ini membuktikan bahwa konverter beroperasi secara C-CCM (Continuous - Continuous Conduction Mode) sesuai dengan desain dan simulasi yang telah dibahas dibab 3 .

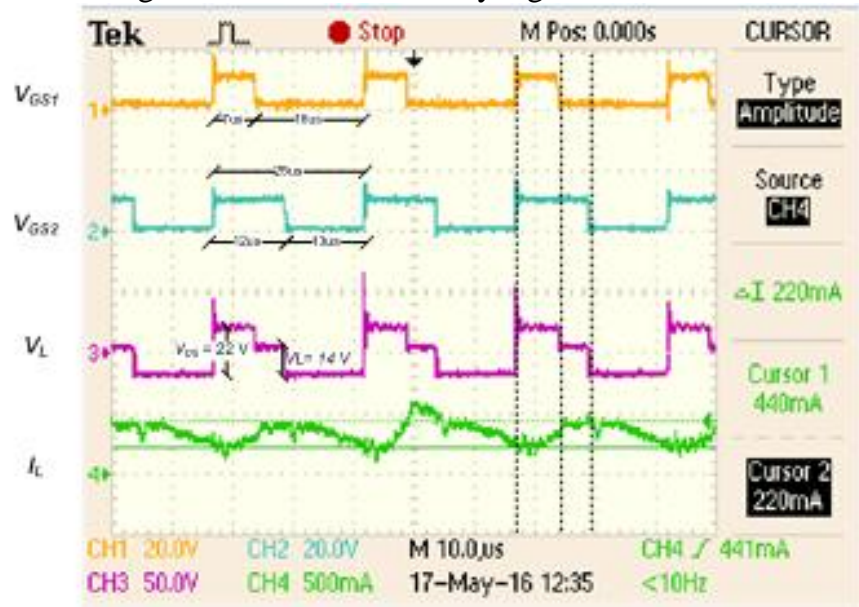

Gambar 6. Bentuk Gelombang tegangan induktor $\left(\mathrm{V}_{\mathrm{L}}\right)$ danarus induktor $\left(I_{L}\right)$ terhadap MOSFET

\section{Pengujian Rasio Konversi}

Pengujian rasio konversi dilakukan dengan menggunakan tegangan input $V_{l}=15 \mathrm{~V}, V_{2}=20 \mathrm{~V}$ dan duty cycle dinaikkan secara bertahap, output terjaga konstan. Gambar 7 di bawah ini menunjukkan grafik hasil pengujian rasio konversi konverter.

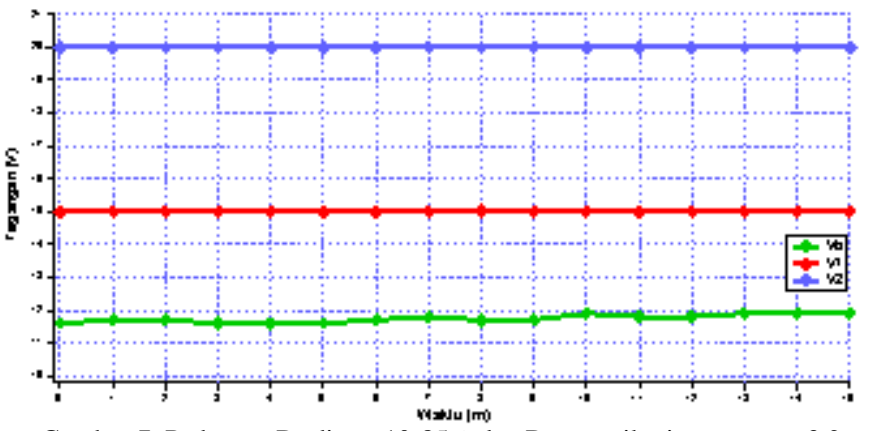

Gambar 7. Pada saat $\mathrm{D}_{1}$ diatur $10-85 \%$ dan $\mathrm{D}_{2}$ mengikuti persamaan 3.2 tegangan output dijaga konstan.

Dari grafik diatas, dapat dilihat ketika konverter bekerja pada semua perubahan duty cycle, output tetap terjaga konstan.

\section{E. Pengujian Efisiensi}

Pengujian efisiensi dilakukan pada tegangan input V1 $=17$ Volt dan $\mathrm{V}_{2}=24$ Volt dengan tegangan output dijaga konstan sebesar \pm 13.8 Volt. Grafik di bawah menunjukkan hasil pengujian efisiensi konverter.

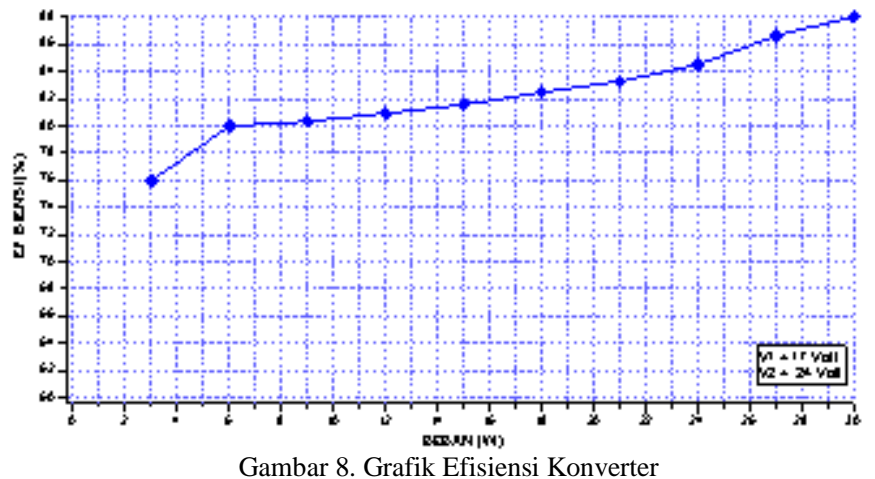

Dari Gambar 8 dapat diketahui bahwa efisiensi tertinggi konverter adalah saat beban maksimal. Selain itu semakin tinggi tegangan input, semakin tinggi pula efisiensi konverter.

\section{F. Pengujian Menggunakan Modul Fotovoltaik}

Pengujian menggunakan modul fotovoltaik dilakukan untuk mengetahui bahwa tegangan output konverter dapat dijaga konstan pada tingkat iradiasi yang berbeda.Gambar 9 di bawah menunjukkan hasil pengujian yang dilakukan pada pukul 09.00 hingga 11.00. Pengujian tidak dilanjutkan dikarenakan pada jam 11.00 hujan. 


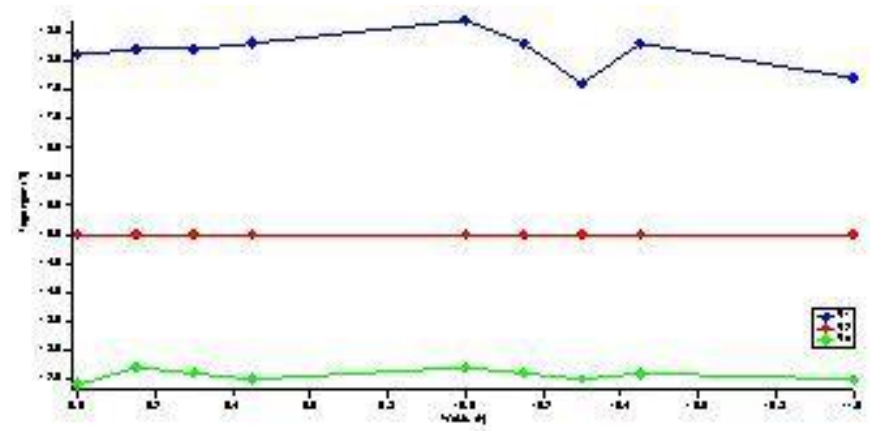

Gambar 9. Grafik Pengujian Menggunakan Modul PV

Dari Gambar 9 dapat diketahui bahwa tegangan output konverter dapat dijaga konstan pada tegangan \pm 13.8 Volt dengan mengubah duty cycle konverter meski tegangan input konverter berubah-ubah akibat perubahan intensitas cahaya matahari yang diserap sel surya.

\section{KESIMPULAN}

Berdasarkan analisis data hasil simulasi dan pengujian implementasi konverter buck multi-input dengan sumber fotovoltaik dan turbin angin, dapt disimpulkan beberapa hal seperti berikut :

1. Konverter buck multi-input yang dipakai adalah 1 (satu) konverter buck yang mempunyai 2 (dua) input yang berkolaborasi menjaga tegangan output tetap konstan.

2. Pengujian efisiensi konverter dilakukan dengan beban 10 - 100\% dari daya $30 \mathrm{~W}$ dan mengalami kenaikan efisiensi saat $20-100 \%$.

3. Duty cycle pertama dan kedua berkolaborasi untuk menjaga output tetap konstan sesuai nilai (besar) tegangan input.

\section{DAFTAR PUSTAKA}

[1]. Nugroho. Aditya. 2012. "Konverter multi-inputUntuk Sistem Pembangkit Hybrid Panel surya Dan Turbin Angin". Surabaya : Institut Teknologi Sepuluh Nopember

[2]. Y.-M. Chen., S.-C Hung., C,-S.Cheng., and Y.-C.Liu., 2005. "Multi-input Inverter for Grid-Connected Hybrid PV/Wind Power Sistem" IEEE Transaction ON 0-78038975

[3]. Lalit Kumar, Shailendra Jain., 2013. "A multiple source DC/DC converter topology" Electrical Power and Energi Systems 51 (2013) 278-291

[4]. Miguel Rodr'1guez., Pablo Fernandez-Miaja., Alberto Rodriguez., February 2010. “A Multiple-Input Digitally Kontrolled Konverter Buck For Envelope Tracking Applications In Radio frequency Power Amplifiers", IEEE Transaction ON POWER ELECTRONICS, VOL. 25, NO. 2

[5]. H. Rashid. Muhammad. 2011. "Power Electronics Handbook 3rd Edition".Butterworth-Heinemann. Florida : University of West Florida

[6]. Hart. Daniel W. 2010. "Power Electronics". Valparaiso. Indiana : Valparaiso University 